Article

\title{
Influencing Factors and Mechanism of Urban Community Tourism Development: A Case Study of Beijing
}

\author{
Ping $\mathrm{Li}^{1}$, Fuyuan Wang ${ }^{2,3, *}$, Xin Zheng ${ }^{4}$ and Jinku Huang ${ }^{5}$ \\ 1 College of Recreation and Tourism, Beijing Sport University, Beijing 100084, China; liping@bsu.edu.cn \\ 2 Institute of Geographic Sciences and Natural Resources Research, Chinese Academy of Sciences, \\ Beijing 100101, China \\ 3 Key Laboratory of Regional Sustainable Development Modeling, Chinese Academy of Sciences, \\ Beijing 100101, China \\ 4 Management College, Ocean University of China, Qingdao 266000, China; 21181211080@stu.ouc.edu.cn \\ 5 Institute of Geomechanics, Chinese Academy of Geological Sciences, Beijing 100081, China; \\ huangjinku@geomech.ac.cn \\ * Correspondence: wangfy.15b@igsnrr.ac.cn; Tel.: +86-188-1164-5838
}

Received: 1 March 2020; Accepted: 31 March 2020; Published: 2 April 2020

check for updates

\begin{abstract}
Urban community tourism (UCT) is a tourism product that promotes the sustainable development of urban communities. This paper constructs an index system of the influencing factors of UCT development (UCTD), which includes five secondary and 15 tertiary indicators. The weights of the indicators are calculated through expert consultation and questionnaire surveys. Based on the index system, this paper empirically evaluates five typical urban tourism communities in Beijing (i.e., Nanluoguxiang, Shichahai, Dashilan, 798 Art District, and Sanlitun) using expert scoring and online comments. We further analyze the impact mechanism of UCTD qualitatively. The findings show that among the secondary indicators, cultural atmosphere and built environment have higher weights than location conditions, specialty shops, and community participation. Among all the tertiary indicators, eight of them (i.e., cultural themes, ornamental value, frequency of cultural activities, store longevity and popularity, cultural institutions, abundance of distinctive buildings, scenic integrity, and community managers' willingness to support UCTD) account for $80 \%$ of the total weight. In terms of the impact mechanism, 15 factors further affect UCTD through demand for authentic travel experiences, reachability perception, travel shopping demand, and stakeholder coordination.
\end{abstract}

Keywords: urban community tourism; influence factors; influence mechanism; Beijing

\section{Introduction}

Over time, cities develop characteristic urban communities through their unique cultural histories, such as Beijing's hutong culture, Shanghai's "lane" culture, and Chengdu's "alley" culture. These specifically reflect the city's geographical environment, living customs, historical heritage, and become the main source of attraction for tourists [1]. Communities are the basic unit where tourists could experience different lifestyles and material products [2]. Urban community tourism (UCT) is a form of tourism showcasing the local culture of an urban community. Following the emergence of tourist infrastructure, an urban community will typically evolve into a tourism community, i.e., a tourism area that provides accommodations, dining, shopping, and other living conditions for both tourists and local residents within the urban district. In this kind of community, the long-accumulated characteristic culture is usually the main attraction [3]. UCT plays a key role in the inheritance and development of 
urban culture. It is conducive to promoting the renewal of community infrastructure and basic services, improving the living environment, thereby realizing the sustainable development of urban tourism.

Previous research on community tourism has focused on rural areas [4,5], including local residents' attitudes toward community tourism [6], community participation [4], the impact of tourism on the community [7], and the planning of community tourism [8]. Specifically, research into local residents' attitudes toward tourism has mainly focused on the content of their perceptions [9], the process of attitude assessment [10], and the changes of their attitude over time [11]. Residents are more concerned about community public service and the environment [12]. Community participation is often investigated through research into the participation of residents, tourists, government, and enterprises [13]. Studies have shown that the positive drivers of community participation include expected gains, emotional attachment to the community, collaborative planning, altruism, and optimism towards conflict resolution [14]. These factors involve individual residents [15], corporate entities [16], and the environment [17]. The impact of tourism on the community is mainly reflected in economic, cultural, and environmental aspects [18]. Community tourism has promoted the local economy [19], better exhibited the local culture [20], increased the number of facilities [21], and led to greater environmental protection [20]. Nevertheless, it has also brought some negative impacts such as raising the cost of living [22], the crime rate [23], and the natural and cultural resource degradation [24]. Research on community tourism planning has investigated the stakeholders' participation in tourism planning and community integration [8]. Tourism planning should take full account of local traditions and residents [8]. To sum up, scholars have carried out detailed and in-depth research on community tourism from different perspectives, but the research on UCT is still less, which cannot meet the practical needs.

In China, research into UCT has developed along several lines: (1) The classification of UCT, which specifically can be divided into cultural, artistic, ecological, and learning types from the perspective of resources. Alternatively, UCT can be classified as leisure, sightseeing, and participatory types $[25,26]$ according to tourists' own purposes. (2) The impact of tourism on urban communities. There are always trade-offs: tourism can increase local employment [27] and promote the inheritance of local characteristic cultures [27], but it may also threaten these cultures [28]. (3) The development model of UCT. Li proposed the protective tourism utilization model for historical and cultural urban communities [29]. Cao summarized three development models of Shanghai's UCT, including the community-enterprise combination model, government-community interaction model, and government-enterprise cooperation model [30]. (4) The influencing factors of UCT development (UCTD). Cao pointed out that tourist demand, tourist supply, and urban tourism space respectively affect the market direction, product development, and spatial layout of UCTD in Shanghai [30]. Tan proposed that community architecture, built environment, community culture, and supporting facilities may influence UCTD [25].

In summary, the research on UCT has mainly focused on the definition of concepts [31], the classification and development model [30], and the impact of tourism on urban communities [27]. In terms of the influencing factors of UCTD, some studies have attempted qualitative analysis from the perspective of community resources and environment, while few articles have combined case studies to evaluate and analyze. Therefore, the focus and purpose of this study is to uncover which factors can determine whether urban communities can be developed as tourism areas and how these factors promote UCTD. Taking Beijing as the case site, a questionnaire survey and the analytic hierarchy process (AHP) method were adopted to identify the influencing factors and mechanism of UCTD. The findings of this study will help policy makers and tourism developers to make suitable policy decisions and development plans for sustainable UCTD. 


\section{Methods}

\section{1. $A H P$}

AHP was first proposed by American operational research scientist Saaty in the early 1970s. It is a decision-making method combining qualitative and quantitative analysis. By analyzing different factors and interrelationships in complex problems, AHP classifies factors according to different levels: target layer (determining research goals), criterion layer (criteria that affect goal achievement), and measure layer (measures to achieve the goals). At each level, a judgment matrix is constructed according to the judgment of relative importance, and the ordering weight of the elements is determined by their eigenvalues. The main steps are as follows: (1) divide the relevant factors into several levels, and establish a multi-level hierarchical structure model; (2) compare the importance of any two factors at the same level and quantify them; (3) based on the criteria of the above same-level factors, compare the factors at the same level with each other, then, build the judgment matrix according to the evaluation criteria to determine the relative importance; (4) calculate the eigenvector of the judgment matrix, and determine the relative importance (weight) of each layer of factors.

\subsubsection{Index System}

Based on a literature review of community tourism and expert questionnaires, this paper constructs an index system of influencing factors of UCTD (Table 1) and explanation of indicators (Table 2). The system incorporates 5 secondary indicators (i.e., cultural atmosphere, built environment, location conditions, specialty shops, and community participation) and 15 tertiary indicators.

Table 1. The index system of factors influencing urban community tourism development (UCTD).

\begin{tabular}{|c|c|c|c|}
\hline $\begin{array}{l}\text { First-Level } \\
\text { Indicators }\end{array}$ & $\begin{array}{l}\text { Secondary } \\
\text { Indicators }\end{array}$ & Tertiary Indicators & Indicator Source \\
\hline \multirow{5}{*}{$\begin{array}{l}\text { Index system of } \\
\text { factors influencing } \\
\text { UCTD }\end{array}$} & $\begin{array}{l}\text { Cultural } \\
\text { atmosphere }\end{array}$ & $\begin{array}{c}\text { Cultural themes } \\
\text { Cultural institutions } \\
\text { Frequency of cultural activities }\end{array}$ & Tan [25]; Wang et al. [32] \\
\hline & Built environment & $\begin{array}{c}\text { Ornamental value } \\
\text { Scenic integrity } \\
\text { Abundance of distinctive buildings }\end{array}$ & Jiang [33] \\
\hline & Location conditions & $\begin{array}{c}\text { Traffic accessibility } \\
\text { Surrounding tourism environment }\end{array}$ & $\begin{array}{l}\text { Supriharjo et al. [34]; } \\
\text { Wang et al. [35] }\end{array}$ \\
\hline & Specialty shops & $\begin{array}{l}\text { Store longevity and popularity } \\
\text { Diversity of store types } \\
\text { Abundance of B\&Bs } \\
\text { Appreciation and experience of } \\
\text { specialty goods }\end{array}$ & Niu et al. [36] \\
\hline & $\begin{array}{l}\text { Community } \\
\text { participation }\end{array}$ & $\begin{array}{c}\text { Residents' willingness to participate } \\
\text { Community managers' willingness } \\
\text { to support } \\
\text { Government's policy support }\end{array}$ & Cheuk et al. [37] \\
\hline
\end{tabular}


Table 2. Explanation of indicators.

\begin{tabular}{|c|c|}
\hline Secondary Indicators & Tertiary Indicators \\
\hline $\begin{array}{l}\text { Cultural atmosphere: community } \\
\text { cultural feelings and experiences }\end{array}$ & $\begin{array}{l}\text { Cultural themes: the community has a clear cultural image } \\
\text { Cultural institutions: the community is equipped with art colleges, } \\
\text { companies, and studios } \\
\text { Frequency of cultural activities: the frequency of cultural festivals or } \\
\text { performances for residents or tourists }\end{array}$ \\
\hline $\begin{array}{l}\text { Built environm } \\
\text { buildings' valu } \\
\text { abun }\end{array}$ & $\begin{array}{l}\text { Ornamental value: the attractiveness of the distinctive buildings to tourists } \\
\text { Scenic integrity: the completeness of the appearance of distinctive buildings } \\
\text { Abundance of distinctive buildings: the richness of the types and quantity of } \\
\text { distinctive buildings }\end{array}$ \\
\hline $\begin{array}{l}\text { Location conditions: traffic } \\
\text { accessibility and tourist attractions } \\
\text { around }\end{array}$ & $\begin{array}{l}\text { Traffic accessibility: the convenience of transportation into the community } \\
\text { Surrounding tourism environment: the tourist attractions around the } \\
\text { community }\end{array}$ \\
\hline $\begin{array}{c}\text { Specialty shops: special goods and } \\
\text { services }\end{array}$ & $\begin{array}{l}\text { Store longevity and popularity: the operation time of specialty shops and } \\
\text { their popularity among tourists } \\
\text { Diversity of store types: the kinds of specialty shops } \\
\text { Abundance of B\&Bs: the types and quantity of B\&Bs } \\
\text { Appreciation and experience of specialty goods: the popularity of specialty } \\
\text { goods among tourists }\end{array}$ \\
\hline $\begin{array}{l}\text { Community participation: the } \\
\text { attitude of residents, community } \\
\text { managers, and local government } \\
\text { towards community tourism }\end{array}$ & $\begin{array}{l}\text { Residents' willingness to participate: the willingness of residents to } \\
\text { participate in community tourism development } \\
\text { Community managers' willingness to support: the willingness of community } \\
\text { managers to support community tourism development } \\
\text { Government's policy support: the willingness of local government to } \\
\text { introduce relevant policies to support community tourism development }\end{array}$ \\
\hline
\end{tabular}

\subsubsection{Indicator Weight Determination}

Construction of the Judgment Matrix and Collection of Weight Scoring Questionnaires

A judgment matrix was constructed according to the basic principle of AHP. Then, we adopted the Delphi method to determine the index weights. We selected a group of experts who taught in tourism-related majors in Beijing's universities and scientific research institutes to evaluate the weights. The specific selection criteria were as follows: (1) their professional rank must be intermediate or above; (2) they have experience of visiting 5 cases in the past three years; (3) their research direction is community tourism, cultural tourism, or tourism geography, and they have published Science Citation Index/Social Science Citation Index/Chinese Social Sciences Citation Index related academic papers; (4) they all have obtained PhD degrees. After several consultations and telephone interviews, 10 qualified experts were finally selected. Then, the evaluation results were collected by means of expert questionnaires.

\section{Consistency Test}

Consistency refers to judging whether the importance of each item in the judgment matrix is consistent. The consistency ratio represents the degree to which the pairwise judgments resemble a purely random set of pairwise comparisons [38]. There were three steps:

(1) Calculate the maximum eigenvalue $\lambda_{\max }$ of the judgment matrix A:

$$
\lambda_{\max }=\frac{1}{n} \sum_{i=1}^{n} \frac{(A * W)_{i}}{W_{i}}
$$

(2) Calculate the consistency index CI:

$$
\mathrm{CI}=\frac{\lambda_{\max }-n}{n-1}
$$


(3) Calculate the random consistency ratio CR:

$$
\mathrm{CR}=\frac{C I}{R I}
$$

When $\mathrm{CR}<0.10$, the judgment matrix is considered to have satisfactory consistency.

\section{Weight Calculation and Characteristics}

The yaahp software was used to aggregate the experts' scores for analysis. After calculation, the $C R$ value was $0.0733<0.10$, indicating that the judgment matrix met the requirements. The next step was to calculate the weight of each indicator. The results (Table 3) showed that the cultural atmosphere had the largest weight, followed by the built environment, specialty shops, and community participation, while the smallest weight was location conditions. For the cultural atmosphere, the largest proportion of influence came from cultural themes, followed by the frequency of cultural activities, and then, the cultural institutions. In terms of the built environment, the largest influencing factors were the ornamental value, scenic integrity, and the abundance of distinctive buildings. In terms of specialty shops, the biggest factor was store longevity and popularity, followed by the diversity of store types and the appreciation and experience of specialty goods, and finally, the abundance of B\&Bs. With respect to community participation, the most important factor was the community managers' willingness to support UCTD, followed by the residents' willingness to participate and the government's policy support. In regard to location conditions, traffic accessibility and the surrounding tourism environment shared the same proportion. Among the tertiary indicators, the largest weights were cultural themes and ornamental value.

Table 3. Index system of factors influencing UCTD.

\begin{tabular}{|c|c|c|c|}
\hline First-Level Indicators & Secondary Indicators & Tertiary Indicators & Index Weight \\
\hline \multirow{15}{*}{$\begin{array}{l}\text { Index system of factors } \\
\text { influencing UCTD }\end{array}$} & \multirow{3}{*}{ Cultural atmosphere } & Cultural themes & 0.25 \\
\hline & & Cultural institutions & 0.07 \\
\hline & & Frequency of cultural activities & 0.09 \\
\hline & \multirow{3}{*}{ Built environment } & Ornamental value & 0.14 \\
\hline & & Scenic integrity & 0.06 \\
\hline & & $\begin{array}{c}\text { Abundance of distinctive } \\
\text { buildings }\end{array}$ & 0.06 \\
\hline & \multirow{2}{*}{ Location conditions } & Traffic accessibility & 0.03 \\
\hline & & Surrounding tourism environment & 0.03 \\
\hline & \multirow{4}{*}{ Specialty shops } & Store longevity and popularity & 0.08 \\
\hline & & Diversity of store types & 0.03 \\
\hline & & Abundance of B\&Bs & 0.02 \\
\hline & & $\begin{array}{l}\text { Appreciation and experience of } \\
\text { specialty goods }\end{array}$ & 0.03 \\
\hline & \multirow{3}{*}{$\begin{array}{l}\text { Community } \\
\text { participation }\end{array}$} & $\begin{array}{l}\text { Residents' willingness to } \\
\text { participate }\end{array}$ & 0.03 \\
\hline & & $\begin{array}{l}\text { Community managers' } \\
\text { willingness to support }\end{array}$ & 0.05 \\
\hline & & Government's policy support & 0.03 \\
\hline
\end{tabular}

\subsection{Case Study}

\subsubsection{Case Selection}

Beijing is a world-famous ancient capital and a modern international city with diverse and distinctive urban tourism communities. This study selected Nanluoguxiang, Shichahai, Dashilan, 798 Art District, and Sanlitun as five UCT cases. Nanluoguxiang has a history of more than 750 years, being first built during the Yuan Dynasty. It is the only "chessboard-style" traditional residential area 
that still completely preserves the hutong courtyards of the Yuan Dynasty. This area includes not only the former residences of historical figures such as Sang-Ko-Lin-Sin, Mao Dun, and Qi Baishi, but also famous art institutions such as the Central Academy of Drama. Shichahai is the largest historical and cultural protection area in Beijing. It is also the only tourism community with an open water area in Beijing. It has the former residences of historical figures such as Gong's Mansion and the residences of Guo Moruo and Song Qingling. Dashilan is adjacent to the Forbidden City, Tiananmen, Temple of Heaven, and the National Museum and is in the central part of old Beijing. After 500 years of change, it still has retained several old Beijing alleys and gradually became a prosperous business district with many time-honored shops. The location of the 798 Art District was once an old industrial area, which later became a special "urban community" where artists lived and worked. Sanlitun is adjacent to the northern embassy district, home to a large number of foreigners, which has led to the rise of streets rich in nightlife. Its subsequent development has incorporated fashion, creativity, and other elements, making it a tourism community hub [39].

The criteria for choosing the five tourism communities as study cases included: (1) high profiles, which helped the accuracy of expert scoring; (2) typical business types, including architectural history, cultural history, traditional commerce, modern art, and fashion shopping; (3) rich comments on online travel sites such as Mafengwo, Ctrip Travel, and Baidu Tourism (all well known in China), which were useful for verifying the results of expert scoring.

\subsubsection{Empirical Evaluation of the Five Cases}

The same 10 experts mentioned above were invited to score the five cases empirically based on the index system of influencing factors for UCTD (each index had a maximum score of five points). Then, the performances of the influencing factors of each community were calculated by combining empirical evaluation values and indicator weights. In order to test the validity of the experts' evaluation results, the article calculated the average scores based on the online reviews of the five cases and compared them with the experts' evaluation scores. If the order of the scores of five cases obtained by the two methods was consistent, the validity of the evaluation results was considered to be good.

\section{Evaluation Results}

\subsection{General Overview of Comprehensive Evaluation Results}

As can be seen from Tables 4 and 5, the coefficients of variation (the ratio of the standard deviation to the arithmetic mean, ideally not exceeding 0.25 ) were all less than 0.25 . Finally, through the integrated analysis, the scores of the five cases were calculated in order from high to low (Figure 1): Shichahai (4.17 points) $>798$ Art District (3.90 points) $>$ Nanluoguxiang (3.85 points) $>$ Dashilan (3.61 points) $>$ Sanlitun (3.08 points).

The final scores of the five communities were calculated based on the number and rating of online comments from Mafengwo, Ctrip Travel, and Baidu Tourism (Table 6), which were: Shichahai (4.65 points) $>798$ Art District ( 4.55 points) $>$ Nanluoguxiang $(4.46$ points $)>$ Dashilan $(4.42$ points $)>$ Sanlitun (4.32 points). The online score ranking was consistent with the expert scoring, which showed that the research results had high reliability. 
Table 4. Comprehensive evaluation results of influencing factors.

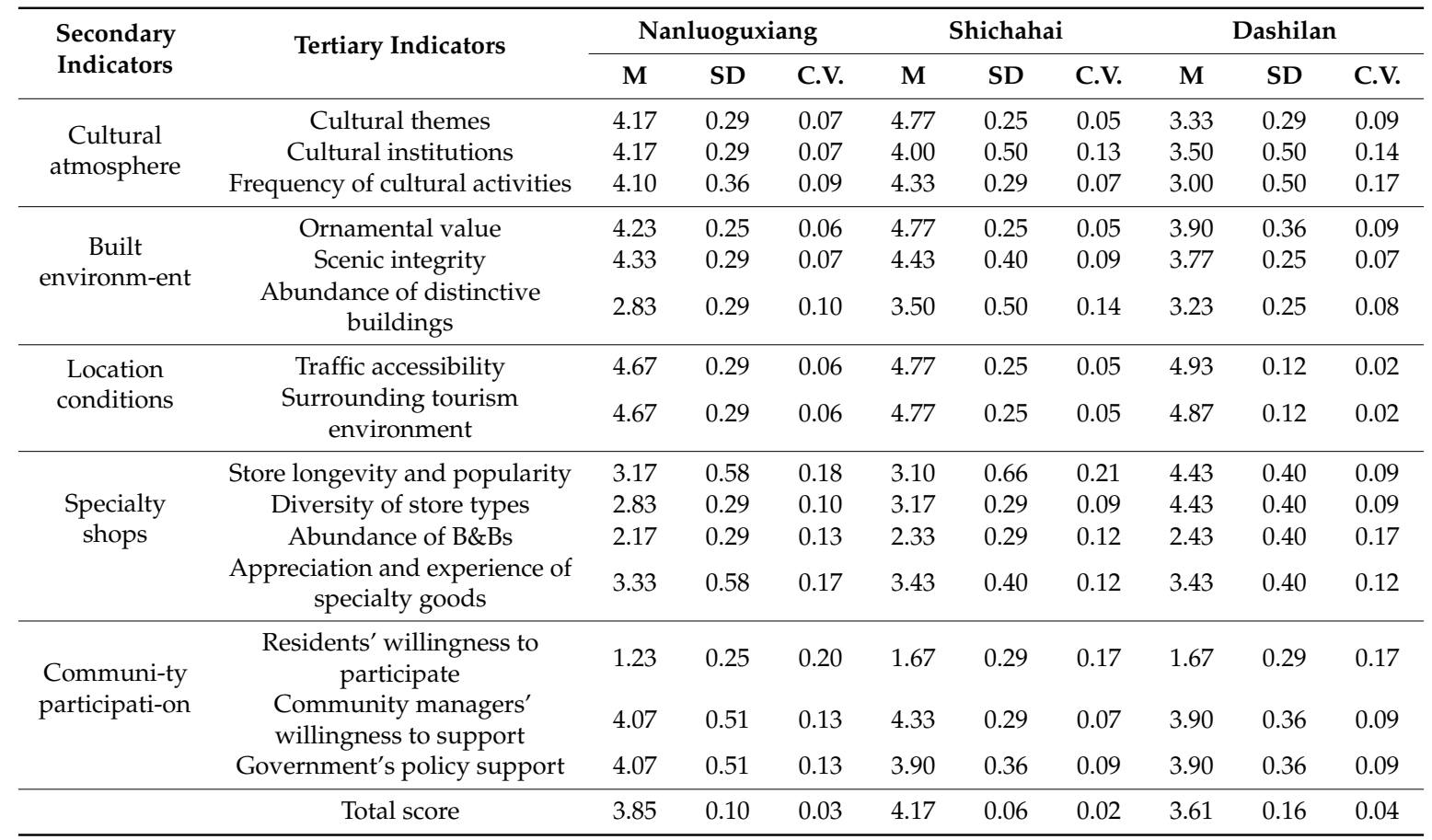

Table 5. Analysis of expert scoring results (continued).

\begin{tabular}{|c|c|c|c|c|c|c|c|}
\hline \multirow{2}{*}{$\begin{array}{l}\text { Secondary } \\
\text { Indicators }\end{array}$} & \multirow{2}{*}{ Tertiary Indicators } & \multicolumn{3}{|c|}{798 Art District } & \multicolumn{3}{|c|}{ Sanlitun } \\
\hline & & M & SD & C.V. & $\mathbf{M}$ & SD & C.V. \\
\hline \multirow{3}{*}{$\begin{array}{l}\text { Cultural } \\
\text { atmosphere }\end{array}$} & Cultural themes & 4.50 & 0.30 & 0.07 & 3.10 & 0.36 & 0.12 \\
\hline & Cultural institutions & 4.87 & 0.12 & 0.02 & 2.50 & 0.50 & 0.20 \\
\hline & Frequency of cultural activities & 4.53 & 0.46 & 0.10 & 3.43 & 0.40 & 0.12 \\
\hline \multirow{3}{*}{$\begin{array}{l}\text { Built } \\
\text { environment }\end{array}$} & Ornamental value & 3.87 & 0.12 & 0.03 & 3.10 & 0.36 & 0.12 \\
\hline & Scenic integrity & 3.23 & 0.25 & 0.08 & 3.90 & 0.36 & 0.09 \\
\hline & Abundance of distinctive buildings & 3.23 & 0.25 & 0.08 & 2.50 & 0.50 & 0.20 \\
\hline \multirow{2}{*}{$\begin{array}{l}\text { Location } \\
\text { conditions }\end{array}$} & Traffic accessibility & 2.73 & 0.64 & 0.24 & 3.77 & 0.25 & 0.07 \\
\hline & Surrounding tourism environment & 2.50 & 0.50 & 0.20 & 3.77 & 0.25 & 0.07 \\
\hline \multirow{4}{*}{$\begin{array}{l}\text { Specialty } \\
\text { shops }\end{array}$} & Store longevity and popularity & 2.60 & 0.53 & 0.20 & 3.33 & 0.76 & 0.23 \\
\hline & Diversity of store types & 3.60 & 0.53 & 0.15 & 4.23 & 0.25 & 0.06 \\
\hline & Abundance of B\&Bs & 1.33 & 0.29 & 0.22 & 1.33 & 0.29 & 0.22 \\
\hline & $\begin{array}{l}\text { Appreciation and experience of } \\
\text { specialty goods }\end{array}$ & 4.23 & 0.25 & 0.06 & 1.77 & 0.25 & 0.14 \\
\hline \multirow{4}{*}{$\begin{array}{l}\text { Community } \\
\text { participation }\end{array}$} & $\begin{array}{l}\text { Residents' willingness to } \\
\text { participate }\end{array}$ & 4.43 & 0.40 & 0.09 & 1.33 & 0.29 & 0.22 \\
\hline & $\begin{array}{l}\text { Community managers' willingness } \\
\text { to support }\end{array}$ & 4.23 & 0.25 & 0.06 & 3.23 & 0.25 & 0.08 \\
\hline & Government's policy support & 4.23 & 0.25 & 0.06 & 3.23 & 0.25 & 0.08 \\
\hline & Total score & 3.90 & 0.11 & 0.03 & 3.08 & 0.02 & 0.01 \\
\hline
\end{tabular}




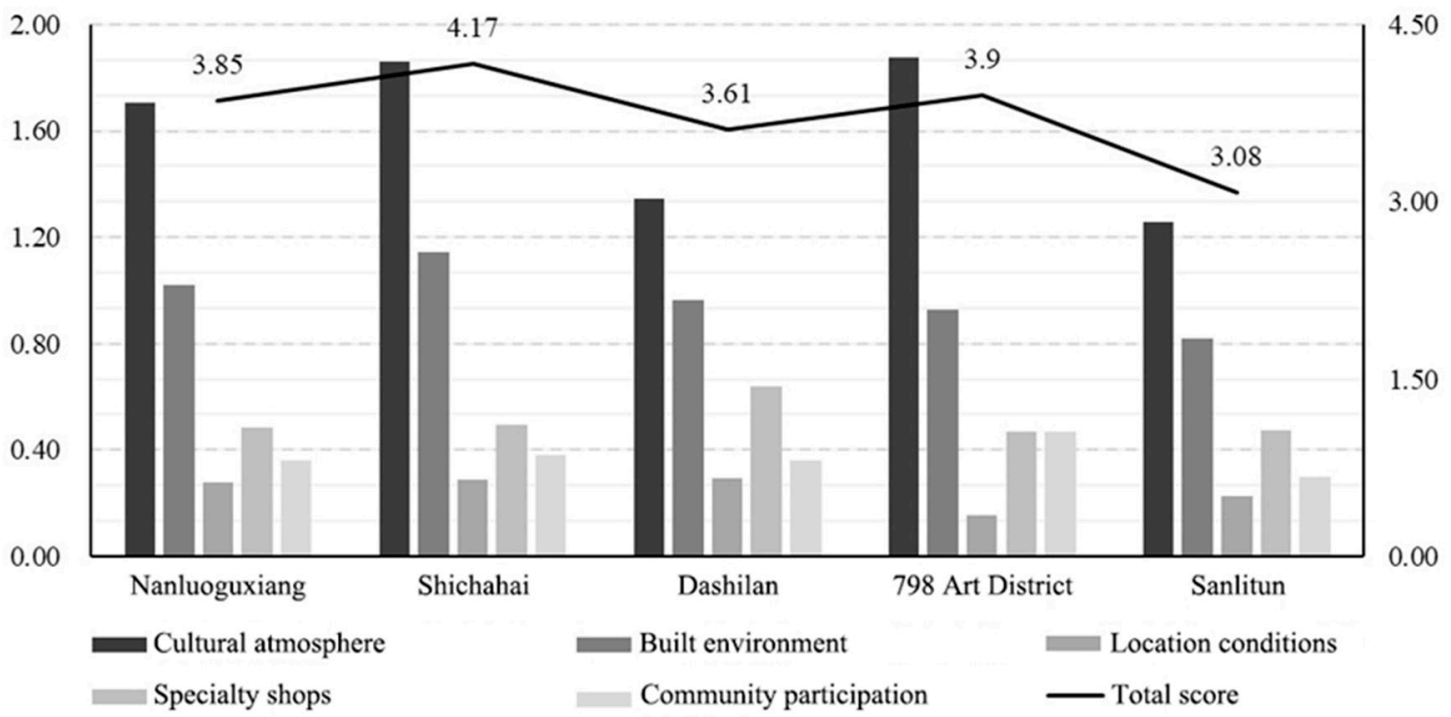

Figure 1. Score graph of secondary indicators for the five cases.

Table 6. Number of online comments by level.

\begin{tabular}{|c|c|c|c|c|c|c|}
\hline \multicolumn{2}{|c|}{ Evaluation (Score) } & \multirow{2}{*}{$\begin{array}{c}\text { Nanluoguxiang } \\
6121\end{array}$} & \multirow{2}{*}{$\begin{array}{c}\text { Shichahai } \\
3839\end{array}$} & \multirow{2}{*}{$\begin{array}{c}\text { Dashilan } \\
1461\end{array}$} & \multirow{2}{*}{$\begin{array}{c}\text { 798 Art District } \\
4090\end{array}$} & \multirow{2}{*}{$\begin{array}{c}\text { Sanlitun } \\
18\end{array}$} \\
\hline \multirow{3}{*}{ Very good (5) } & Mafengwo & & & & & \\
\hline & Ctrip Travel & 1437 & 982 & 435 & 617 & 278 \\
\hline & Baidu Tourism & 1645 & 486 & 297 & 1387 & 517 \\
\hline \multirow{3}{*}{ Good (4) } & Mafengwo & 829 & 292 & 228 & 367 & 1 \\
\hline & Ctrip Travel & 809 & 429 & 230 & 298 & 108 \\
\hline & Baidu Tourism & 1458 & 505 & 393 & 1088 & 458 \\
\hline \multirow{3}{*}{ General (3) } & Mafengwo & 828 & 292 & 228 & 367 & 1 \\
\hline & Ctrip Travel & 252 & 88 & 72 & 87 & 37 \\
\hline & Baidu Tourism & 425 & 97 & 142 & 323 & 154 \\
\hline \multirow{3}{*}{ Poor (2) } & Mafengwo & 140 & 23 & 35 & 51 & 0 \\
\hline & Ctrip Travel & 33 & 20 & 10 & 6 & 3 \\
\hline & Baidu Tourism & 69 & 16 & 4 & 38 & 27 \\
\hline \multirow{3}{*}{ Very poor (1) } & Mafengwo & 140 & 23 & 35 & 51 & 0 \\
\hline & Ctrip Travel & 31 & 18 & 11 & 6 & 5 \\
\hline & Baidu Tourism & 36 & 0 & 8 & 25 & 8 \\
\hline \multicolumn{2}{|c|}{ Mean score } & 4.46 & 4.65 & 4.42 & 4.55 & 4.32 \\
\hline
\end{tabular}

Note: data as of May 9, 2019.

\subsection{Evaluation Results of Tourism Communities}

\subsubsection{Shichahai Community}

The performances of tourism communities acquired from the empirical evaluation were introduced and analyzed respectively in the next step. For the Shichahai community, its built environment, location conditions, and cultural atmosphere were relatively highly evaluated. Among them (Figure 2), Shichahai's cultural atmosphere score was slightly lower than the 798 Art District, but higher than Nanluoguxiang, Dashilan, and Sanlitun. Specifically, the cultural themes of Shichahai's urban leisure opportunities were very prominent. Hutongs, waters, boats, rickshaws, Yinding Bridge, and original music in Houhai made up Shichahai's cultural characteristics.

Shichahai's built environment scored highest among the five cases. As regards scenic integrity, Shichahai covers a larger area than that of Nanluoguxiang, and it has kept many complete courtyard buildings and alleys. Shichahai has abundant distinctive buildings, such as lofts, temples, bridges, 
princely residences, historic residential buildings, hutongs, and many other distinctive cultural buildings, giving it obvious advantages among the five cases. In terms of the frequency of specific words in online reviews, Shichahai had more terms describing the built environment than the other four cases [39].

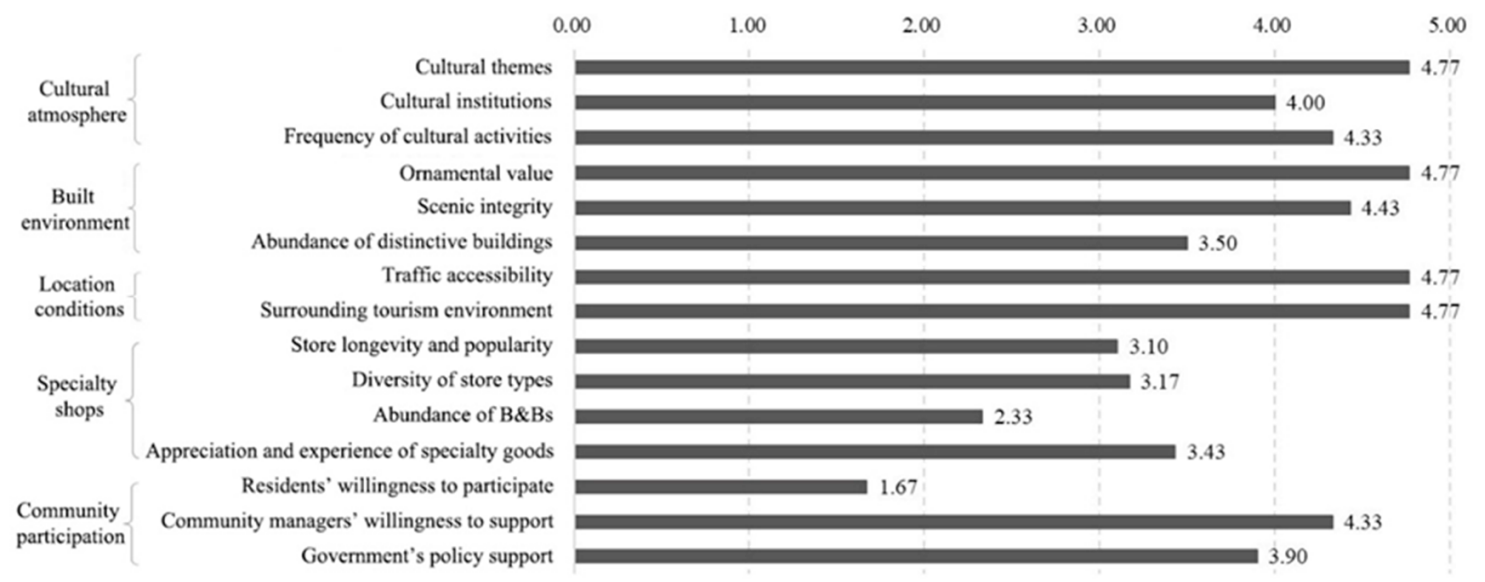

Figure 2. Tertiary indicators' score graph of Shichahai UCT.

The scores of the location conditions for Shichahai were almost the same as those of Dashilan and Nanluoguxiang. All three areas are located within the Second Ring Road of old Beijing's urban area, making them convenient to reach by road. Shichahai's palpable cultural atmosphere makes it a hub of urban leisure, boasting vast bodies of water, an accumulation of historic hutongs, and the culturally rich nightlife area of historic Houhai. The Shichahai community scored relatively poorly on specialty shops and community participation. The community managers' willingness to support UCTD scored the highest among the five cases, mainly because they have done much work on the renovation of community streets and the demolition of dilapidated houses.

\subsubsection{Art District Community}

Previous studies have shown that visitors value the cultural atmosphere most highly (70.34\%) [40] and are most concerned about their cultural artistic experience and feelings. The cultural atmosphere of the 798 Art District scored relatively high. The 798 Art District was officially named a "National Cultural and Creative Industry Base" by the state in 2006 [40]. Its various art forms such as design, painting, and sculpture are attractive to tourists. The 798 Art District has the largest number of artists and art institutions among the five cases. It has various cultural activities, such as art exhibitions and festivals, to promote cultural exchange. In terms of built environment, as the 798 Art District was formerly a state-owned industrial site, the architectural style is relatively uniform, with a score between 3.23 and 3.87 (Figure 3).

Although the 798 Art District is located within the urban area of Beijing, it is relatively remote and less accessible compared with the other cases. Previous research has shown that tourists give low scores on traffic and parking conditions in the 798 Art District [40] (Figure 4). In addition, the nearest $4 \mathrm{~A}$ and $5 \mathrm{~A}$ scenic spots around the district are more than $10 \mathrm{~km}$ away, leading to lower scores in surrounding tourism environment. The district's scores on specialty shops were also not outstanding. Only the score for the appreciation and experience of specialty goods was high, at 4.23 . This is mainly because the art exhibitions and festivals provide visitors with a platform to access performance art and other art experiences. More than half of the shops in the 798 Art District have been in business for only 1-4 years. The stores' longevity and popularity are relatively weak, with a score of only 2.6. In terms of abundance of B\&Bs, there are relatively few because of the district's weak surrounding tourism environment and the short visiting times (typically half a day). 


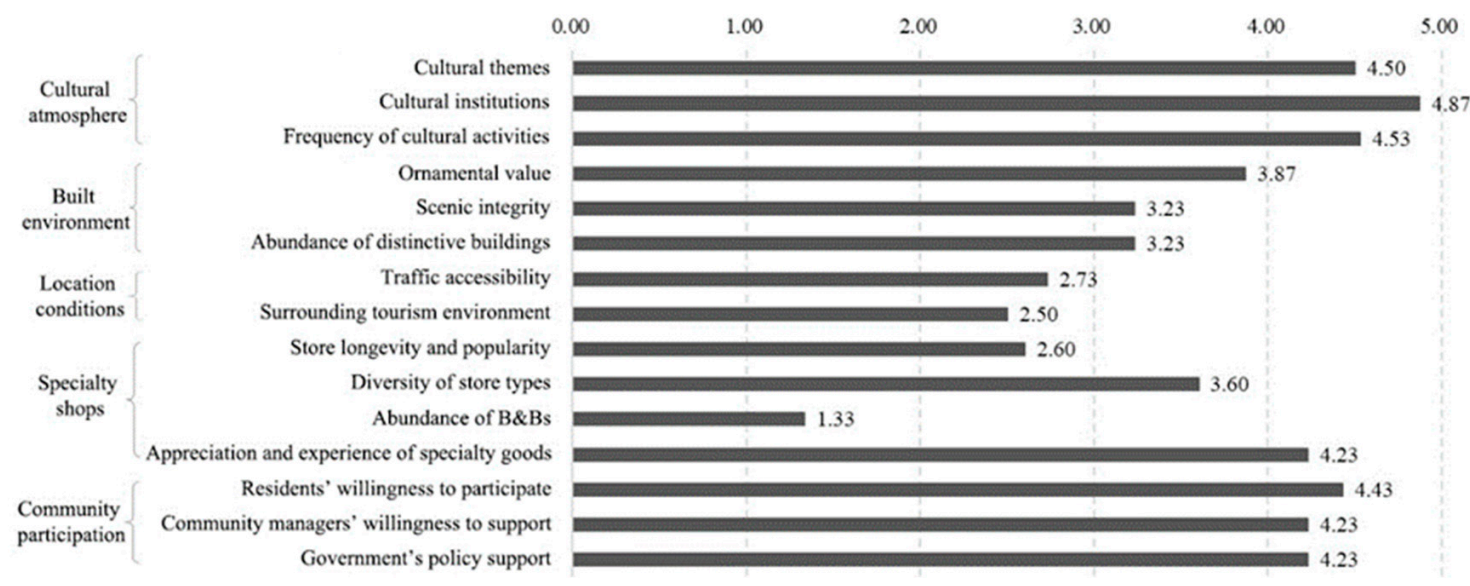

Figure 3. Tertiary indicators' score graph of the 798 Art District UCT.

In terms of community participation, the artists in the 798 Art District are themselves creators of and participants in art. As the "residents" of 798 Art District, the works created by local artists have vitally participated in the district's development. Regarding policy support, the government has adopted a series of measures, such as the recognition of the 798 Art District as a "National Cultural and Creative Industry Base", promoting the district's sustainable development.

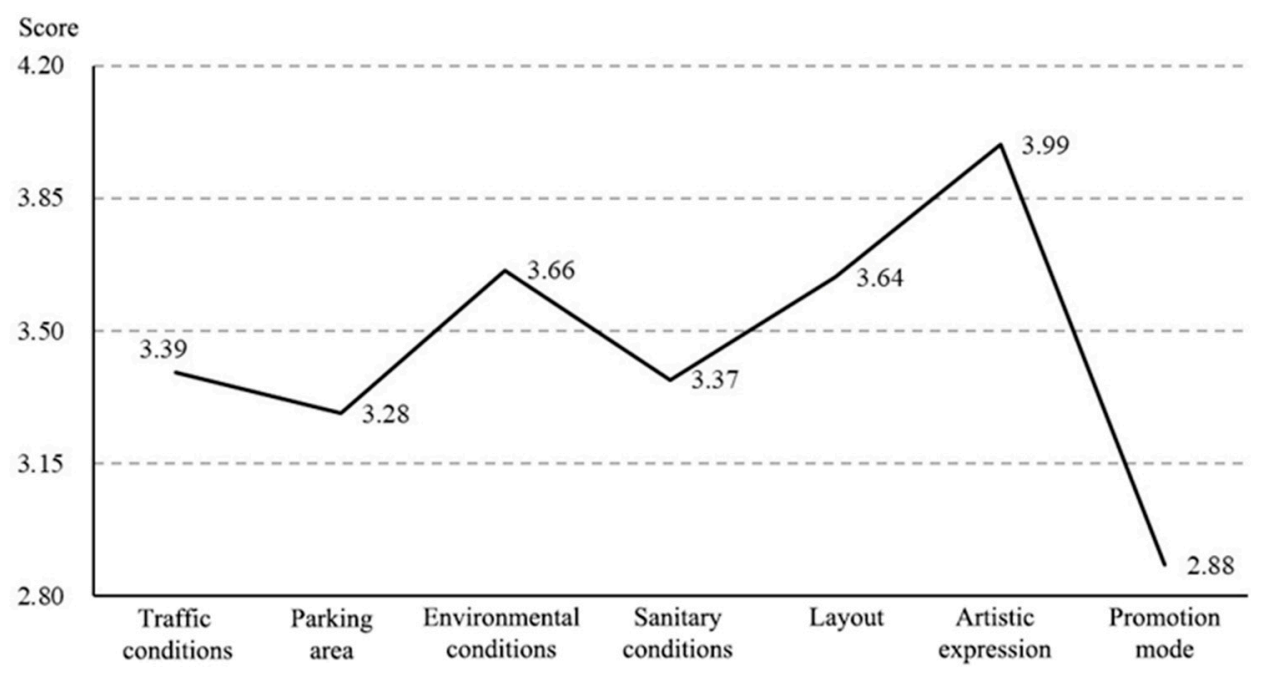

Figure 4. Mean score of visitor perception in the 798 Art District [40].

\subsubsection{Nanluoguxiang Community}

In terms of the scores of the secondary indicators, Nanluoguxiang's evaluation value was in the middle level of the five cases. The cultural atmosphere scored lower than the 798 Art District and Shichahai. This was due to the over-commercialization of Nanluoguxiang, which has affected the authenticity of the old Beijing streets, while the artistic atmosphere of the 798 Art District and the old Beijing history and bar culture of Shichahai are perceived as "real" [41]. With respect to the frequency of cultural activities, Nanluoguxiang scored lower than the 798 Art District and Shichahai, but higher than Dashilan and Sanlitun. Since 2006, Nanluoguxiang has held cultural festivals every year, such as the alley festival in 2006-2012, the traditional folk cultural festival of "Insects awaken the gong and drum" in 2010-2013, and the Nanluoguxiang Theater Festival in 2010-2019.

Nanluoguxiang's built environment score was lower than Shichahai. The district is inferior to Shichahai both in the number of cultural relic protection sites and the types of cultural relic buildings. In terms of scenic integrity, Nanluoguxiang scored lower than Shichahai, but higher than the other three 
cases. Nanluoguxiang has made some recent attempts to update and transform the architectural style, such as the construction of the Ju'er hutong. It has tried to maintain the integrity of the characteristic style in the process of street facade reconstruction. With respect to location conditions, Nanluoguxiang, Shichahai, and Dashilan had similar scores because of the advantageousness of their geographical positions. More specifically, Nanluoguxiang has obvious advantages in terms of traffic accessibility and surrounding tourism environment, with many popular tourist attractions nearby.

Nanluoguxiang's score in specialty shops was lower than Dashilan, mainly because there are few time-honored and well-known shops. The score on the diversity of store types was low (Figure 5). Due to the rent increase in recent years, more and more shops have switched to selling snacks, while the number of stores selling traditional wares has decreased. In terms of the abundance of B\&Bs, the quadrangle-themed hotels in Nanluoguxiang highlight the characteristics of the old Beijing hutong culture. Regarding community participation, the scores of Nanluoguxiang, Shichahai, and Dashilan were similar, all of which were lower than the 798 Art District. Field investigations have found that local residents are not enthusiastic about community participation. With respect to community managers' willingness and government's policy to support UCTD, the Nanluoguxiang Street Management Committee has formulated a robust and detailed plan. The plan establishes chambers of commerce to regulate local businesses and relevant policies in response to the excessive commercialization, such as using the main street storefronts to establish a museum of intangible cultural heritage.

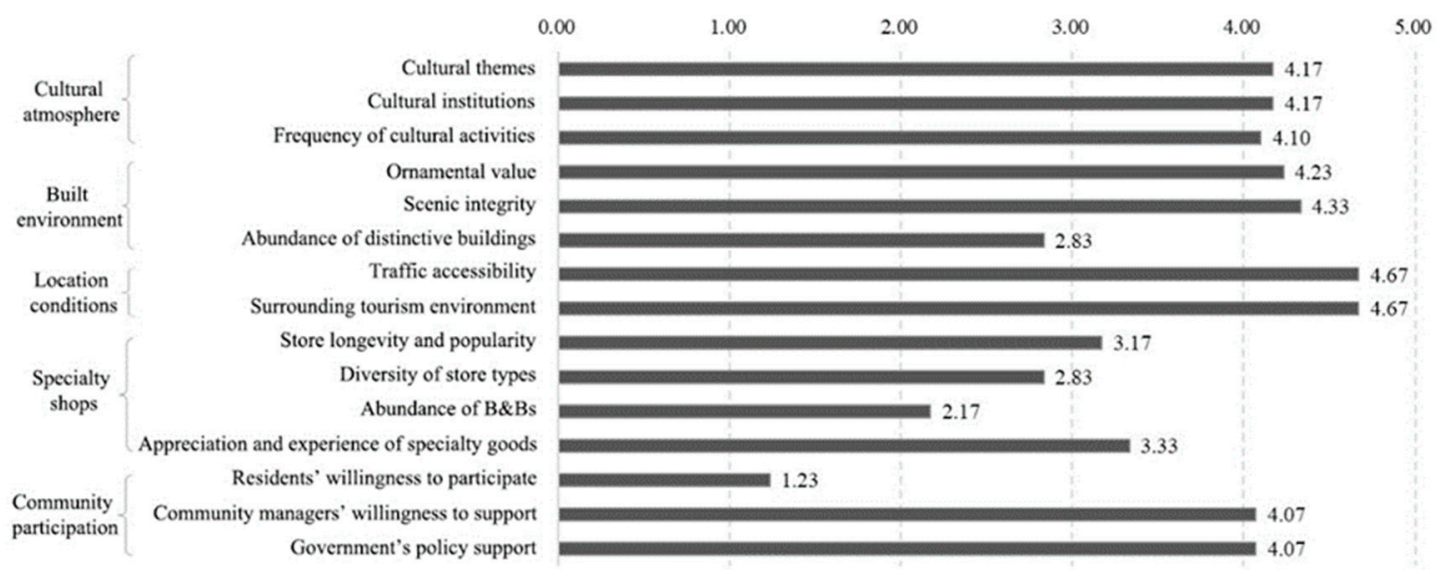

Figure 5. Tertiary indicators' score graph of Nanluoguxiang UCT.

\subsubsection{Dashilan Community}

The scores of Dashilan's cultural atmosphere, built environment, and community participation were intermediate among the five cases. The location conditions and specialty shops had the highest scores (Figure 6), as the district features obvious advantages. Dashilan is located in the central area of Beijing, adjacent to the Forbidden City, Tiananmen, Temple of Heaven, and the National Museum. It has advantages in traffic accessibility. In relation to specialty shops, Dashilan has the best situation among the five cases, being one of the oldest commercial streets in Beijing, with a complete range of retailers and the most famous brands. The community's score on store longevity and popularity was incomparably superior to the other cases: with some well-established businesses that are hundreds of years old, Dashilan has become a central part of Beijing's brand. With its array of clothing, food, tea, and medicine stores, the score for the diversity of store types reached 4.43 points. The high score on the abundance of $B \& B$ s was due to the convenient geographical location, adjacent to multiple tourist attractions. Moreover, the old Beijing hutong residential areas of Dashilan are relatively compact, with a large number of $B \& B s$, of which it has the most among the five cases. Previous research has also confirmed that Dashilan had the highest score in terms of tourists' perception of accessibility and venerable shops [42]. It is thus beyond doubt that location conditions and specialty shops are two of the most prominent aspects of Dashilan. 


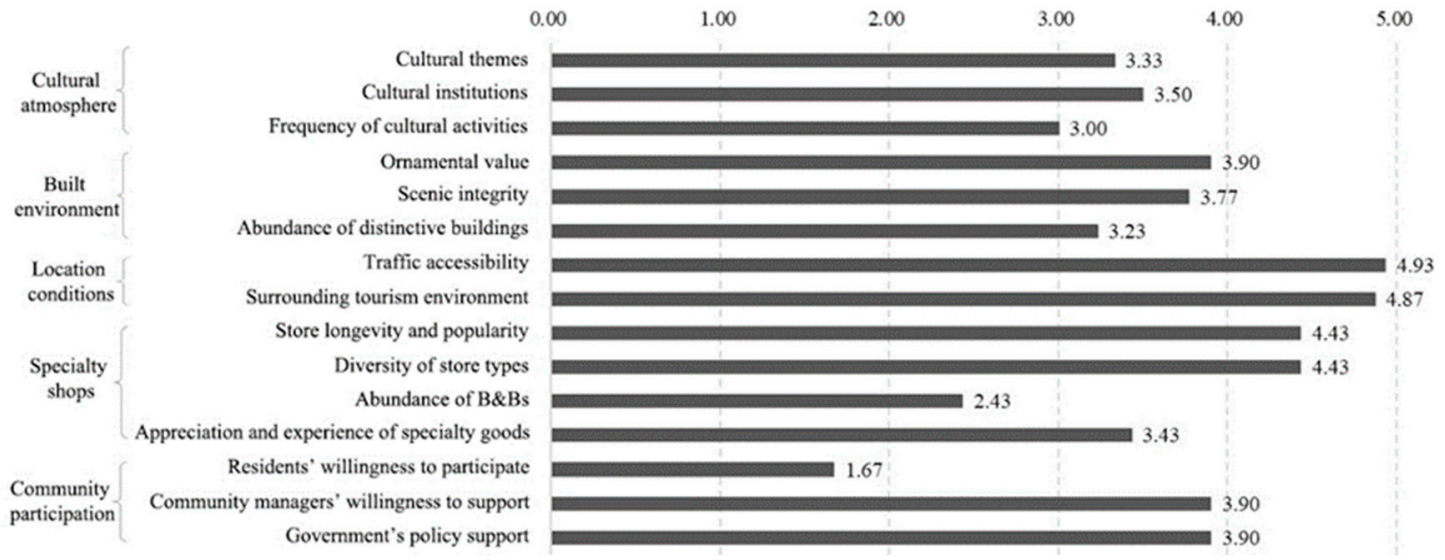

Figure 6. Tertiary indicators' score graph of Dashilan UCT.

\subsubsection{Sanlitun Community}

Sanlitun scored the lowest on cultural atmosphere, built environment, specialty shops, and community participation. In terms of the cultural atmosphere, the evaluation scores of cultural themes and institutions were low (Figure 7). Sanlitun's historical heritage has no advantage over the other four cases. With the increasing number of embassies, Sanlitun has gradually acquired cultural features such as fashion outlets and bars, but these make it obviously distinct from the culture of traditional Chinese communities.

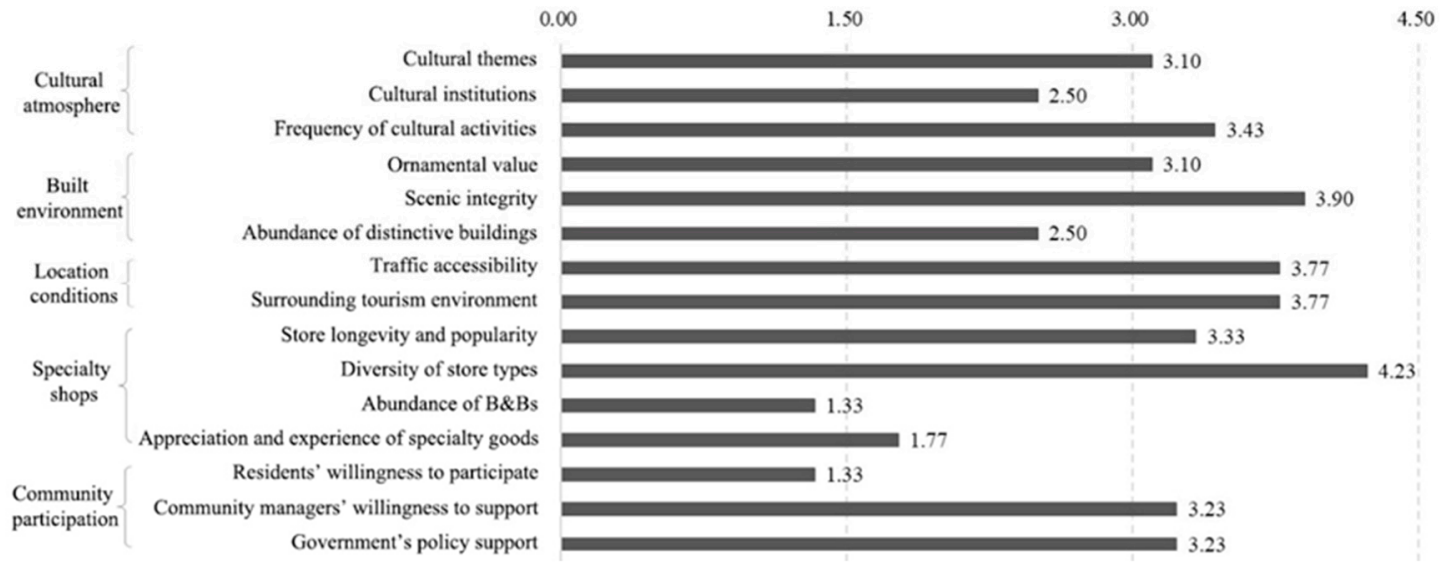

Figure 7. Tertiary indicators' score graph of Sanlitun UCT.

In terms of the built environment, the ornamental value and the abundance of distinctive buildings had low scores. Although the embassy buildings and the buildings in Taikoo Li have their own historical and cultural characteristics, compared with the other four cases, these characteristics are not especially noteworthy. Sanlitun's score on traffic accessibility and the surrounding tourism environment atmosphere both reached 3.77 points, which indicated that its location is relatively good. In terms of specialty shops, because the current business profile is dominated by modern brands, the store's longevity and popularity had a low score at 3.33 points. However, as the main shopping location in this area, Taikoo $\mathrm{Li}$ is studded with retailers offering famous domestic and foreign brands, boosting the score of the diversity of store types to 4.23 .

With respect to community participation, Sanlitun also scored lower than the other four cases. This area's attractiveness to tourists is lower than the other districts due to a number of factors, (i.e., residents' willingness to participate, community managers' willingness to support UCTD, government's policy support). Indeed, all three aspects are weaker than in the other four cases. In addition, the residents 
here have participated less in development. This substantiated the view of Sreekumar et al. [43] that only a small number of residents benefit from tourism development.

\section{Impact Mechanism Analysis}

\subsection{Influence Paths of Cultural Atmosphere}

Cultural themes and institutions can influence visitors' perception of the cultural atmosphere through community features and cultural events. The frequency of cultural activities and residents' willingness to participate influence the interaction between host and guest. The common cultural characteristic of Nanluoguxiang, Shichahai, and Dashilan is the old Beijing hutong culture, while each area also has its cultural atmosphere. The shops in Nanluoguxiang showcase Chinese cultural creativity. Shichahai has a unique urban leisure culture and bar culture and has also produced the Houhai music culture in more recent times. Dashilan's time-honored business culture has a centuries-long history, which has great appeal for tourists. The 798 Art District has the characteristics of post-modern art and culture. Sanlitun has succeeded in creating an atmosphere conducive to fashion and bar culture. However, the overdevelopment of modern commercial functions such as shopping and dining is further resulting in the disappearance of the cultural authenticity of historical communities. Therefore, the cultural atmosphere and built environment of Sanlitun were evaluated relatively poorly, indicating that cultural atmosphere would influence UCTD through cultural authenticity of communities.

\subsection{Impact Paths of the Built Environment}

The impact of the built environment on UCTD is mainly mediated through tourists' pursuit of architectural authenticity. The ornamental value, the scenic integrity, and the abundance of distinctive buildings affect the cultural profile of an urban area, thereby influencing the authenticity of tourists' experiences of the community as a built-up area. Among the five cases, Shichahai's built environment was highly rated, because the existing historical buildings are complete and well-preserved, and the authenticity of the experience is thus high. Next were Nanluoguxiang and Dashilan, both of which have many historical and cultural buildings. The 798 Art District's and Sanlitun's built environment scores were both relatively low, indicating that the Bauhaus architectural style in the former and the embassy district and characteristic commercial buildings of Taikoo Li in the latter are less attractive than traditional historical buildings.

\subsection{Influence Paths of Location Conditions}

The traffic accessibility of a tourism community and the surrounding tourism environment affect the UCTD through the tourists' reachability perception. Traffic accessibility is a locational advantage of a community. The atmosphere of the surrounding tourism environment affects both the community and the surrounding tourism space. Among the five cases, Dashilan had the best geographical location, being located in the city center. It has advantages in both traffic accessibility and the surrounding tourism environment. Shichahai and Nanluoguxiang have similar geographical locations and therefore close scores. Sanlitun has advantages in terms of traffic accessibility and the surrounding tourism environment, while the 798 Art District is far from the city center and lacks well-known tourist attractions.

\subsection{Impact Paths of Specialty Shops}

The degree of influence of specialty shops on UCT is second only to the cultural atmosphere and the built environment. Specialty shops can meet the conventional "shopping" needs of tourists. However, to fulfill tourists' "search for newness and difference," a store's "specialty" is particularly important. A community's score on the longevity and popularity of stores mainly refers to the brand power of old-fashioned stores. Generally, established shops have a deep cultural heritage and are associated with historical stories, which make them a tourist attraction in their own right. A high 
diversity of store types can meet the diversified travel needs of tourist shopping. The appreciation and experience of specialty goods can provide a unique product purchase experience. In terms of both the longevity and popularity of the stores and the diversity of store types, Dashilan's centuries-old specialty shops are the most distinctive. In other cases, certainly, they also have their own characteristics.

\subsection{Impact Paths of Community Participation}

A tourism community is based first on the residential needs of the community residents and second on the tourism service. The life of community residents is part of the community culture. For example, residents who are engaged in the human rickshaw business serve as "explainers" of the community culture. Community managers' and government's willingness to support UCTD promote tourism through stakeholder coordination. Merchants in the 798 Art District are both creators of the artistic atmosphere and participants. Most residents of Nanluoguxiang, Shichahai, Dashilan, and Sanlitun indirectly participate in community tourism through house leasing. Specifically, residents in these areas typically work outside of the community where they live, in contrast to rural communities where residents can directly participate in the operation of the tourism community. In addition, although the community residents in these districts have a negative attitude toward direct participation, the community managers are actively willing to support UCTD, which keeps the balance among the stakeholders.

In general, these influencing factors ultimately affect UCTD through demand for authentic travel experiences, reachability perception, travel shopping demand, and stakeholder coordination (Figure 8).

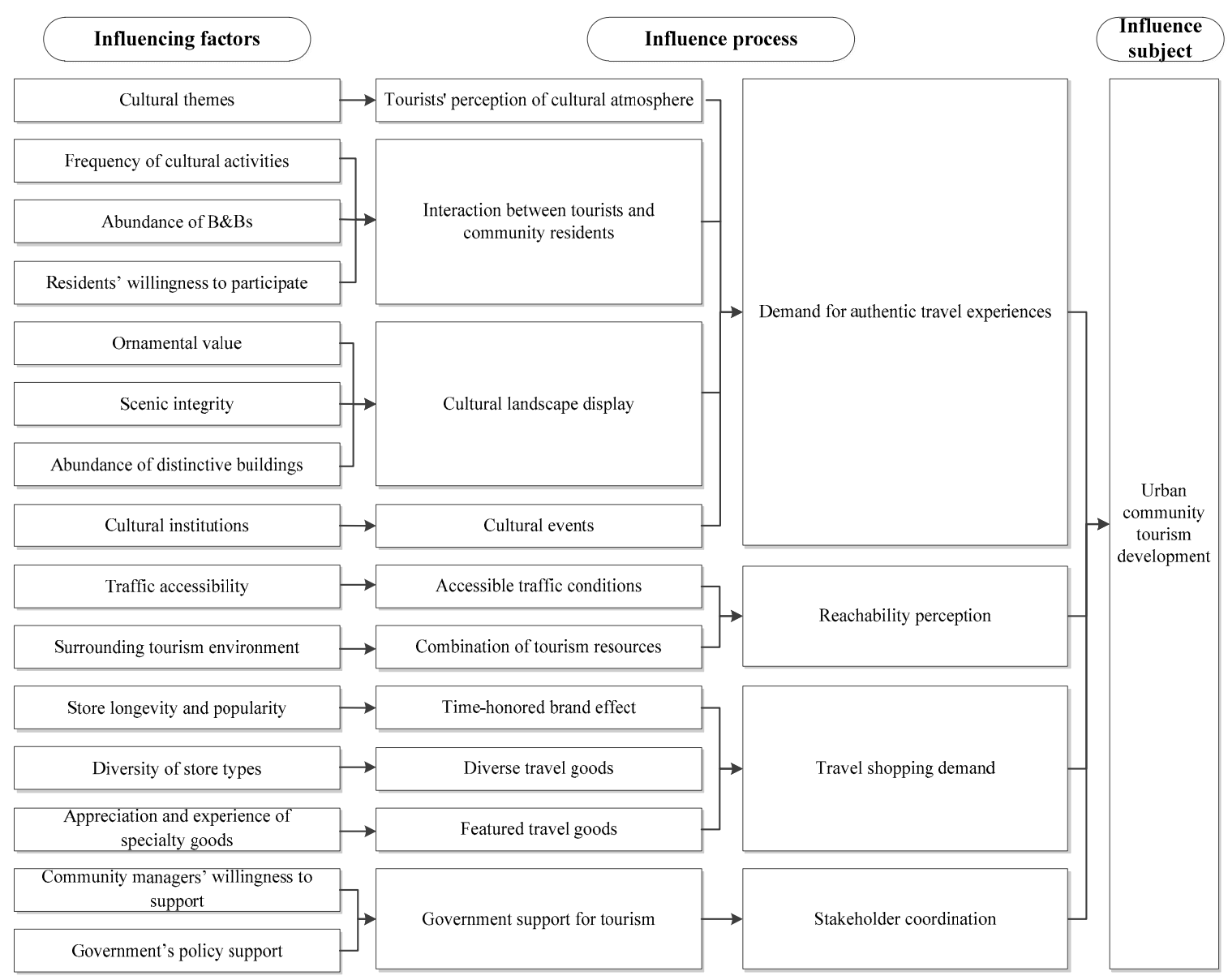

Figure 8. Impact mechanism of UCTD. 


\section{Conclusions and Management Recommendations}

\subsection{Conclusions and Discussions}

The influencing factors of UCTD in descending order of importance were cultural atmosphere, built environment, specialty stores, community participation, and location conditions. In other words, the distinctive cultural atmosphere and architectural style were the key factors for UCTD. In addition, specialty shops played a role in conveying the unique culture of a community. Tourists could deepen their cultural experience by purchasing locally distinctive products, which verified the importance of "history and culture" to tourism destinations uncovered in previous studies [42].

It stands to reason that the most important influencing factors of UCTD were the distinctive culture and architecture, as these are also the basis and premise of UCTD. The distinctive culture is the "spirit" and the "core" value of a community. Meanwhile, the architecture is the "material" of an urban community, which is an important carrier of the "representation" of the core culture. This verified the former view [19] that historical centers and buildings are visitors' favorite places except for museums in urban areas. It is also consistent with the previous research, which confirmed that culture, buildings, and stores are an important part of tourists' perception of UCT [39]. The traffic accessibility, surrounding tourism environment, diversity of store types, and appreciation and experience of specialty goods had smaller weights. The abundance of B\&Bs had the least impact on UCTD. Tourists could choose from a wide range of star-rated and express hotels, so characteristic B\&Bs played a relatively small role.

The impact of community participation was small, which was one of the differences between urban and rural tourism communities. Previous studies in rural community tourism have shown that residents' attitudes and community leadership had a significant positive impact, while government's support had little impact [37]. However, our results showed that residents' willingness to participate and government's policy support were slightly less important than community managers' willingness to support. The reason was that, on the one hand, most urban residents had their own jobs in the city, while most rural residents directly participated in the rural community tourism for their livelihood. Tourism development may disturb urban residents' original life, so they were less willing to participate in tourism development than rural residents, which was similar to the study of Mccool, S, F. et al. [44]. On the other hand, the community managers could help the government to implement public service policies, and this is conducive to maintaining a good relationship between tourists and local residents, so as to enhance residents' sense of identity to UCTD and tourists' sense of belonging to the tourism destinations. This was consistent with the findings of Wang Y. et al. [35].

Location conditions had little impact because the urban infrastructure was already relatively complete, which resulted in the high accessibility of urban tourism communities. Travel by road is more convenient in urban areas, as there are fewer problems such as barriers to entry. However, the relative disadvantage of a location within a city will still affect the community tourism score. For example, the 798 Art District is far from the city center, and the surrounding area lacks well-known tourist attractions, which resulted in the lower score on location condition. In addition, in terms of the impact mechanism of UCTD, 15 factors further influenced UCTD through demand for authentic travel experiences, reachability perception, travel shopping demand, and stakeholder coordination.

\subsection{Management Recommendations}

\subsubsection{Strengthening Community Cultural Themes and Improving Ornamental Value}

From the research findings, cultural themes and ornamental value played a key role in UCTD, especially cultural themes. Policy makers and tourism developers could enhance community cultural themes by hosting a series of community festival cultural events, increasing the community's intelligent cultural interpretation system, developing cultural experience tourism products, and so on. For excavating the building ornamental value, first of all, policy makers and tourism developers should 
repair and protect historic buildings, distinctive buildings, and celebrities' buildings, then develop appropriate tourism activities depending on distinctive buildings, such as research trips and science trips. Based on historical events, holding performances and other activities in historical buildings would increase the viewing experience for tourists.

\subsubsection{Introducing Control Policies on Business Formats}

The business formats are one of the ways to showcase community culture. For newly developed urban tourism communities, over-commercialization is rarely a problem. However, as community tourism gradually reaches the mature stage, problems may arise that affect the authenticity of culture. From the analysis of network review data, the tourism development of the Nanluoguxiang, 798 Art District, Shichahai, and Dashilan communities has already bred excessive commercialization, as businesses have grown too fast and squeezed out the original culture's living space. Business formats within the community should ensure that cultural authenticity is not affected by over-commercialization. Attention should be paid to avoiding the loss of distinctive community culture due to the overload of snack streets and commodity stores. Therefore, government departments should work with community enterprises and local residents to formulate countermeasures, thereby controlling the types, quantity, and proportion of businesses, encouraging the differentiation and branding development of community tourism-based stores.

\subsubsection{Issuing Policies to Support Special Goods}

Special goods such as local food, handicrafts, and intangible cultural heritage are a window to show visitors the unique culture of a community. In the field survey, it was found that almost all tourism communities had no relevant subsidies or support policies for such businesses. Therefore, management departments should set up incentives to encourage the development of characteristic cultural products, such as encouraging business owners' sense of honor and responsibility by formulating reward and punishment policies.

\subsubsection{Formulating Subsidy Policies for Community Participation}

Community participation needs attention for the sustainable development of UTC. The results of the field survey showed that some community residents living near the tourist area are highly antagonized by tourism development. For example, traffic jams, occupation of public toilets, and noise are common in the tourism peak season, which have negative impacts on local residents' life, while residents living far from the tourist areas are more supportive of UCT. They argued that it is an effective measure to raise the profile of Beijing, with a positive effect on the protection and inheritance of historical culture. For the residents affected by tourism, however, UCTD occupies their living space and interferes with their quality of life, for which they have not received any subsidies. Hence, it is necessary to formulate compensation policies to improve residents' appreciation and support for UCTD, such as providing activities at preferential rates for residents in the off-season.

\subsection{Research Innovation, Limitations, and Prospects}

This study established the influencing factors and the mechanism of UCTD, providing a reference for the government to select appropriate UCTD areas. However, there were some limitations in terms of data collection and research method. First, the evaluation system was developed from an expert perspective, without considering the perception of other stakeholders such as tourists and residents. Second, compared to the mail survey conducted in this study, face-to-face expert interviews may help obtain more information concerning UCTD, such as the specific reasons behind the scores, thereby enriching the results of the study. Last, the quantitative statistical analysis of the impact mechanism was restricted by the lack of official statistics of the five communities. As a result, subsequent research could adopt a tourist-based or resident-based perspective to explore the influencing factors of UCTD. 
Further research can also combine questionnaire surveys, in-depth interviews, text content analysis, and structural equation models to reveal the more detailed influencing mechanism of UCTD.

Author Contributions: Conceptualization, P.L. and F.W.; methodology, P.L. and F.W.; software, P.L.; formal analysis, F.W.; investigation, P.L. and F.W.; resources, P.L. and F.W.; writing, original draft preparation, P.L.; writing, review and editing, P.L., F.W., X.Z., and J.H. All authors read and agreed to the published version of the manuscript.

Funding: This research received no external funding.

Conflicts of Interest: The authors declare no conflict of interest.

\section{References}

1. MacCannell, D. Empty Meeting Grounds: The Tourist Papers; Routledge: London, UK, 1992.

2. Richards, G.; Hall, D. Tourism and Sustainable Community Development; Routledge: London, UK, 2000.

3. Li, P.; Chen, T.; Wang, X.G.; Wang, F.Y. Review on Urban Community Tourism Research in China. Urban Dev. Stud. 2016, 23, 85-90.

4. Sudesh, P.; Vikneswaran, N.; Sridar, R. Community participation in rural tourism: Towards a conceptual framework. Procedia Soc. Behav. Sci. 2014, 144, 290-295.

5. Juma, L.O.; Khademi-Vidra, A. Community-Based Tourism and Sustainable Development of Rural Regions in Kenya: Perceptions of the Citizenry. Sustainability 2019, 11, 4733. [CrossRef]

6. Joo, D.; Tasci, A.D.A.; Woosnam, K.M.; Maruyama, N.U.; Hollas, C.R.; Aleshinloye, K.D. Residents' attitude towards domestic tourists explained by contact, emotional solidarity and social distance. Tour. Manag. 2018, 64, 245-257. [CrossRef]

7. Suess, C.; Baloglu, S.; Busser, J.A. Perceived impacts of medical tourism development on community wellbeing. Tour. Manag. 2018, 69, 232-245. [CrossRef]

8. Del Chiappa, G.; Atzeni, M.; Ghasemi, V. Community-based collaborative tourism planning in islands: A cluster analysis in the context of Costa Smeralda. J. Destin. Mark. Manag. 2018, 8, 41-48. [CrossRef]

9. Woo, E.; Uysal, M.; Sirgy, M.J. Tourism Impact and Stakeholders Quality of Life. J. Hosp. Tour. Res. 2016, 42, 260-286. [CrossRef]

10. Lundberg, E. The level of tourism development and resident attitudes: A comparative case study of coastal destinations. Scand. J. Hosp. Tour. 2015, 15, 266-294. [CrossRef]

11. Li, X.R.; Hsu, C.H.C.; Lawton, L.J. Understanding residents' perception changes toward a mega-event through a dual-theory lens. J. Travel Res. 2015, 54, 396-410. [CrossRef]

12. Sinclair-Maragh, G.; Gursoy, D.; Vieregge, M. Residents' perceptions toward tourism development: A factor-cluster approach. J. Destin. Mark. Manag. 2015, 4, 36-45.

13. Mayaka, M.; Croy, W.G.; Wolfram Cox, J. A dimensional approach to community-based tourism: Recognising and differentiating form and context. Ann. Tour. Res. 2019, 74, 177-190. [CrossRef]

14. Dragouni, M.; Fouseki, K. Drivers of community participation in heritage tourism planning: An empirical investigation. J. Herit. Tour. 2018, 13, 237-256. [CrossRef]

15. Moghavvemi, S.; Woosnam, K.M.; Paramanathan, T.; Musa, G.; Hamzah, A. The effect of residents' personality, emotional solidarity, and community commitment on support for tourism development. Tour. Manag. 2017, 63, 242-254. [CrossRef]

16. Hallak, R.; Brown, G.; Lindsay, N.J. Examining tourism SME owners' place attachment, support for community and business performance: The role of the enlightened self-interest model. J. Sustain. Tour. 2013, 21, 658-678. [CrossRef]

17. Taylor, S.R. Issues in measuring success in community-based Indigenous tourism: Elites, kin groups, social capital, gender dynamics and income flows. J. Sustain. Tour. 2017, 25, 1-17. [CrossRef]

18. Lee, T.H.; Jan, F. Can community-based tourism contribute to sustainable development? Evidence from residents' perceptions of the sustainability. Tour. Manag. 2019, 70, 368-380. [CrossRef]

19. Zamfir, A.; Corbos, R.A. Towards Sustainable Tourism Development in Urban Areas: Case Study on Bucharest as Tourist Destination. Sustainability 2015, 7, 12709-12722. [CrossRef]

20. Lee, T.H.; Jan, F.; Yang, C. Conceptualizing and measuring environmentally responsible behaviors from the perspective of community-based tourists. Tour. Manag. 2013, 36, 454-468. [CrossRef] 
21. Brunt, P.; Courtney, P. Host perceptions of sociocultural impacts. Ann. Tour. Res. 1999, 26, 493-515. [CrossRef]

22. Lee, C.; Back, K. Examining structural relationships among perceived impact, benefit, and support for casino development based on 4 year longitudinal data. Tour. Manag. 2006, 27, 466-480. [CrossRef]

23. Ap, J. Residents' perceptions on tourism impacts. Ann. Tour. Res. 1992, 19, 665-690. [CrossRef]

24. Bowers, J. Developing sustainable tourism through ecomuseology: A case study in the Rupununi region of Guyana. J. Sustain. Tour. 2016, 24, 758-782. [CrossRef]

25. Tan, H.J. Research on Urban Community Tourism Development; Dongbei University of Finance and Economics: Dalian, China, 2007.

26. Shen, X.F. Research on Internationalization Development Mode of Urban Community Tourism; Zhejiang Gongshang University: Hangzhou, China, 2008.

27. Cheng, Y. Research on the Residents' Perception to Tourism Impact in Urban Community-Case Study of Shanghai Old Street; East China Normal University: Shanghai, China, 2007.

28. Zhang, L.S. An ethnics reflection of city community tourism. J. Xinyang Norm. Univ. 2004, 17, 308-310.

29. Li, X. District Memory and Tourism Identity-Research on Protective Tourism Utilization of Barkhor Street Historical and Cultural District in Lhasa; Minzu University of China: Beijing, China, 2013.

30. Cao, Y. Research on the Development Model of Shanghai Urban Community Tourism; Shanghai Normal University: Shanghai, China, 2013.

31. Wang, Y.M.; Cheng, Y.; Gong, W.; Lv, S. The "Xintiandi" pattern in the internationalization of urban community tourism. Tour. Sci. 2006, 20, 36-42.

32. Wang, D.G.; Niu, Y.; Lu, L.; Qian, J. Tourism spatial organization of historical streets- A postmodern perspective: The examples of Pingjiang Road and Shantang Street, Suzhou, China. Tour. Manag. 2015, 48, 370-385. [CrossRef]

33. Jiang, R.S. The Construction of Historic Building Tourism Resources Evaluation System and the Empirical Research; Fujian Normal University: Fuzhou, China, 2009.

34. Supriharjo, R.D.; Rahmawati, D.; Santoso, E.B.; Setiawan, R.P.; Pradinie, K. Factors Influencing Community-based Heritage Sustainability in Kampung Kemasan, Gresik. Procedia Soc. Behav. Sci. 2016, 227, 498-502. [CrossRef]

35. Wang, Y.; Xu, X.X. Influential factors of rural tourism development in perspective of community- A case of Hangzhou. Econ. Geogr. 2015, 35, 203-208.

36. Niu, Y.; Wang, D.G. Influence mechanism and innovation of tourism development pattern of historic streets based on the perspective of tourists: A case of Pingjiang Road of Suzhou. Geogr. Res. 2015, 34, 181-196.

37. Cheuk, S.; Lo, M.; Atang, A. Rural Tourism Destination Performance in East Malaysia: Influencing Factors from the Communities' Perspective. J. Sustain. Dev. 2015, 8, 124-138. [CrossRef]

38. Hummel, J.M.; Bridges, J.F.P.; IJzerman, M.J. Group Decision Making with the Analytic Hierarchy Process in Benefit-Risk Assessment: A Tutorial. Patient-Patient-Cent. Outcomes Res. 2014, 7, 129-140. [CrossRef]

39. Li, P.; Chen, T.; Wang, F.Y.; Wang, X.G. Urban tourism community image perception and differentiation based on online comments: A case study of Beijing. Geogr. Res. 2017, 36, 1106-1122.

40. Ning, Z.; Jin, S. An inspection of 798 artistic zone: A cultural tourist attraction in Beijing. Tour. Trib. 2008, 23, $57-62$.

41. Zhao, H.X. The study of historic districts under the "Authenticity" theory: A case study of Shichahai and Nanluoguxiang area in Beijing. Hum. Geogr. 2019, 34, 47-54.

42. Zhao, P.J.; Ma, B.W. Research Based on Sense of Place in the Culture Context Influence during Historical District Renewal: Case Study of Beijing Qianmen Dashilan Area. Urban Dev. Stud. 2015, 22, 63-72.

43. Sreekumar, T.T.; Parayil, G. Contentions and Contradictions of Tourism as Development Option: The Case of Kerala, India. Third World Q. 2002, 23, 529-548. [CrossRef]

44. Mccool, S.F.; Martin, S.R. Community Attachment and Attitudes toward Tourism Development. J. Travel Res. 1994, 32, 29-34. [CrossRef]

(C) 2020 by the authors. Licensee MDPI, Basel, Switzerland. This article is an open access article distributed under the terms and conditions of the Creative Commons Attribution (CC BY) license (http://creativecommons.org/licenses/by/4.0/). 